\title{
Obstructive Uropathy by an Extraosseous Multiple Myeloma: A Case Report
}

\author{
Nicholas Robillard ${ }^{\mathrm{a}, \mathrm{c}}$, Jean Ethier ${ }^{\mathrm{b}}$
}

\begin{abstract}
Multiple myeloma, characterized by plasma cell proliferation in the bone marrow, is the second most common hematologic malignancy. According to the 2003 Criteria for the Classification Monoclonal Gammapathies, Multiple Myeloma and Related Disorders, a clonal proliferation of plasma cells that occurs outside the bone marrow is referred to a plasmocytoma. Infrequently, patients with multiple myeloma are discovered to have an extramedullary plasma cell proliferation which cannot be categorized in the subgroups established by the International Myeloma Working Group. This clinical situation has been coined extraosseous multiple myeloma in recent medical literature. The following report is that of an extraosseous multiple myeloma causing an obstructive uropathy and acute renal failure. A brief literature review in relation to the case will complement the analysis of this rare finding.
\end{abstract}

Keywords: Multiple Myeloma; Extraosseous Multiple Myeloma; Plasmocytoma; Obstructive uropathy; Renal failure.

\section{Introduction}

Multiple myeloma is a monoclonal proliferation from a single plasma cell. It is the second most frequent hematologic malignancy after the non-Hodgkin lymphoma. It frequently presents as lytic bone disease, recurrent infections, hypercalcemia and acute renal failure. Infrequently, multiple myeloma can present in association with extramedullary plasma

Manuscript accepted for publication May 22, 2013

${ }^{a}$ Internal Medicine, Montreal University Hospital Centers, 3840

St-Urbain Street, Montreal, Quebec, H2W 1T8, Canada

${ }^{\mathrm{b}} \mathrm{Nephrology,} \mathrm{Montreal} \mathrm{University} \mathrm{Hospital} \mathrm{Centers,} 3840$ St-Urbain

Street, Montreal, Quebec, H2W 1T8, Canada

${ }^{\mathrm{c}}$ Corresponding author: Nicholas Robillard, Internal Medicine,

Montreal University Hospital Centers, 3840 St-Urbain Street,

Montreal, Quebec, H2W 1T8, Canada.

Email: n.robillard@umontreal.ca

doi: http://dx.doi.org/10.4021/jmc1257w cell proliferation. According to some reports, less than 4-5\% of multiple myelomas are associated with an extraosseous involvement [1-3]. These cases are said to represent a more aggressive subtype of multiple myeloma. The following report presents the case of a patient with an IgA Lamda monoclonal serum peak protein and lytic bone disease that presented an acute renal failure (ARF) secondary to an obstructive uropathy in presence of multiple extramedullary retroperitoneal lymph node plasmacytomas. A literature review pertaining to extraosseous multiple myeloma is presented in relation to the following case report.

\section{Case Report}

A 61-year-old female patient was referred to the department of nephrology for the incidental finding of an elevated creatinine (creatinine $=229 \mu \mathrm{mol} / \mathrm{L}$ ) discovered at the time of a visit at the emergency room for an unrelated symptomatology of gastroesophageal reflux disease. Four months earlier, her creatinine value was of $92 \mu \mathrm{mol} / \mathrm{L}$.

Her past history was non-contributive and was composed of: High blood pressure, dyslipidemia, type 2 diabetes, fibromyalgia, anxiety and depressive disorder. Her ques-

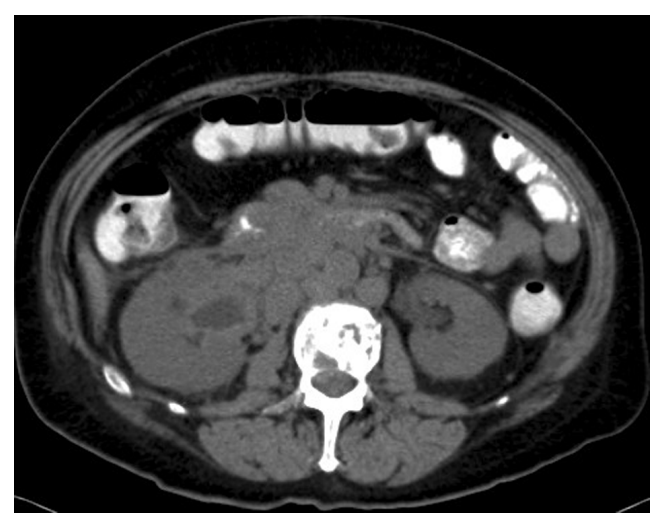

Figure 1. Abdomino-pelvic CT. A diffuse retroperitoneal ganglionnary process with infiltration of the right renal pelvis and the proximal right ureter associated with multiple osseous lytic lesions. 


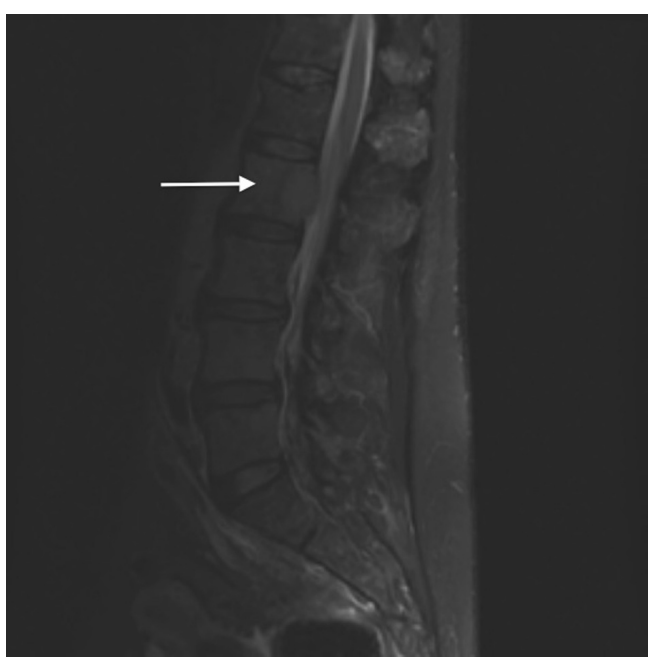

Figure 2. MRI of the spine. The arrow shows the epidural infiltration at the level of $\mathrm{L} 2$, which was not associated with a spinal or foraminal stenosis.

tionaire was unrevealing for any cause of acute renal failure. There were no new medications or constitutional changes in her health except for a weight loss that she attributed to loss of appetite in relation to a recent personal hardship. However, she admitted having occasional lower back pain. The physical exam did not reveal any new information.

Primary lab results showed a stable creatinine level at $232 \mu \mathrm{mol} / \mathrm{L}$ and a normocytic normochromic anemia. A protein electrophoresis and immunofixation demonstrated an IgA protein serum monoclonal peak of $40.50 \mathrm{~g} / \mathrm{L}(\mathrm{N}=0.66$ $4.00 \mathrm{~g} / \mathrm{L}$ ) and the elevated expression of a Lamda light chain at $3420.00 \mathrm{mg} / \mathrm{L}(\mathrm{N}=5.7-26.3 \mathrm{mg} / \mathrm{L})$. A renal ultrasound showed bilateral hydronephrosis with multiple retroperitoneal adenopathies. A computed tomographic evaluation of retroperitoneal process was then undertaken (Fig. 1).

An MRI of the spine was done to evaluate the bone lesions seen on the abdominal scan. It showed multiple lytic lesions of the spine and pelvis with epidural infiltration without foraminal or spinal stenosis and multiple pathologic vertebral fractures at T5, T9, and L2 (Fig. 2). The radiological findings were compatible with multiple myeloma.

A retrograde ureteropyelography was done to evaluate a potential obstructive uropathy. An attempt for the installation of double J ureteral catheter failed and the patient developed an oligo-anuric state that required a right percutaneous nephrostomy. Despite these maneuvers, the patient's anuria persisted and she rapidly necessitated dialysis treatments.

To elucidate the nature of the retroperitoneal process, a biopsy was done of a right iliac fossa retroperitoneal mass. Histopathological examination of the mass revealed sheets and cords of plasma cells of varying degrees of differentiation with little intervening stroma. Immunohistochemistry showed widespread positivity for CD138, Lambda light chain, and IgA heavy chain, and negativity for Kappa light chain and IgG heavy chain, confirming the diagnosis of plasmacytoma (Fig. 3).

Shortly after her retroperitoneal biopsy, the patient was admitted to the ICU for a hemorrhagic shock. Dialysis was initiated soon after. A few days after her stay in the intensive care unit, the patient developed a massive subarachnoidal hemorrhage from which she died. The patient died a week and a half after her admission to the hospital. This series of complications made it impossible for the treating physicians to perform a bone biopsy or a 24-hour urine collection for Bence Jones proteinuria. No autopsy was performed on the body, to respect the wishes of the family.

\section{Discussion}

In recent years, an attempt to establish a classification and definition of the different monoclonal gammopathies has been made [4]. Several criteria have been used to establish a difference between solitary plasmacytoma of the bone, extramedullary plasmacytoma and the diagnostic of multiple myeloma. However, the literature is less clear in the case of an association between an intramedullary and an extramedullary proliferation of plasma cell clones. Most authors depict this situation as an aggressive multiple myeloma with visceral extension.

According to two post mortem examination of 52 and 62 patients, extraskeletal spread of multiple myeloma was identified in 63.5 and $67 \%$ of cases respectively [5, 6]. Many sites of tumoral spread have been identified in different case reports and radiological reviews $[1,7]$. The extramedullary extension of the disease is often cited as a relapse after an initial treatment has been initiated. In 2004, Damaj G. et al reviewed 432 cases of multiple myeloma to better characterize the type of patients presenting with "extraosseous multiple myeloma". Nineteen patients were found to have an extraskeletal spread of their disease. Neither the stage of the disease, the LDH level, or the type of immunoglobulin was found to have an impact on the developpement of extraosseous multiple myeloma [3]. In contrast, a clinicopathologic study of 150 patients with multiple myeloma by Puschel W and Kunath $\mathrm{K}$ found that extraosseous involvement in multiple myeloma was more frequent in IgG and IgA monoclonal gammopathies. They also noted a tendency for hemorrhagic diathesis with IgA multiple myeloma [8].

What makes this case unusual is that multiple myeloma was not the initial presentation of the patient. The patient presented with an acute renal failure in the context of a bilateral hydronephrosis brought on by multiple retroperitoneal lymph node plasmacytomas that caused an obstructive uropathy.

After review of the literature, 3 cases of acute obstructive uropathy induced by ureter compression made by retroperi- 

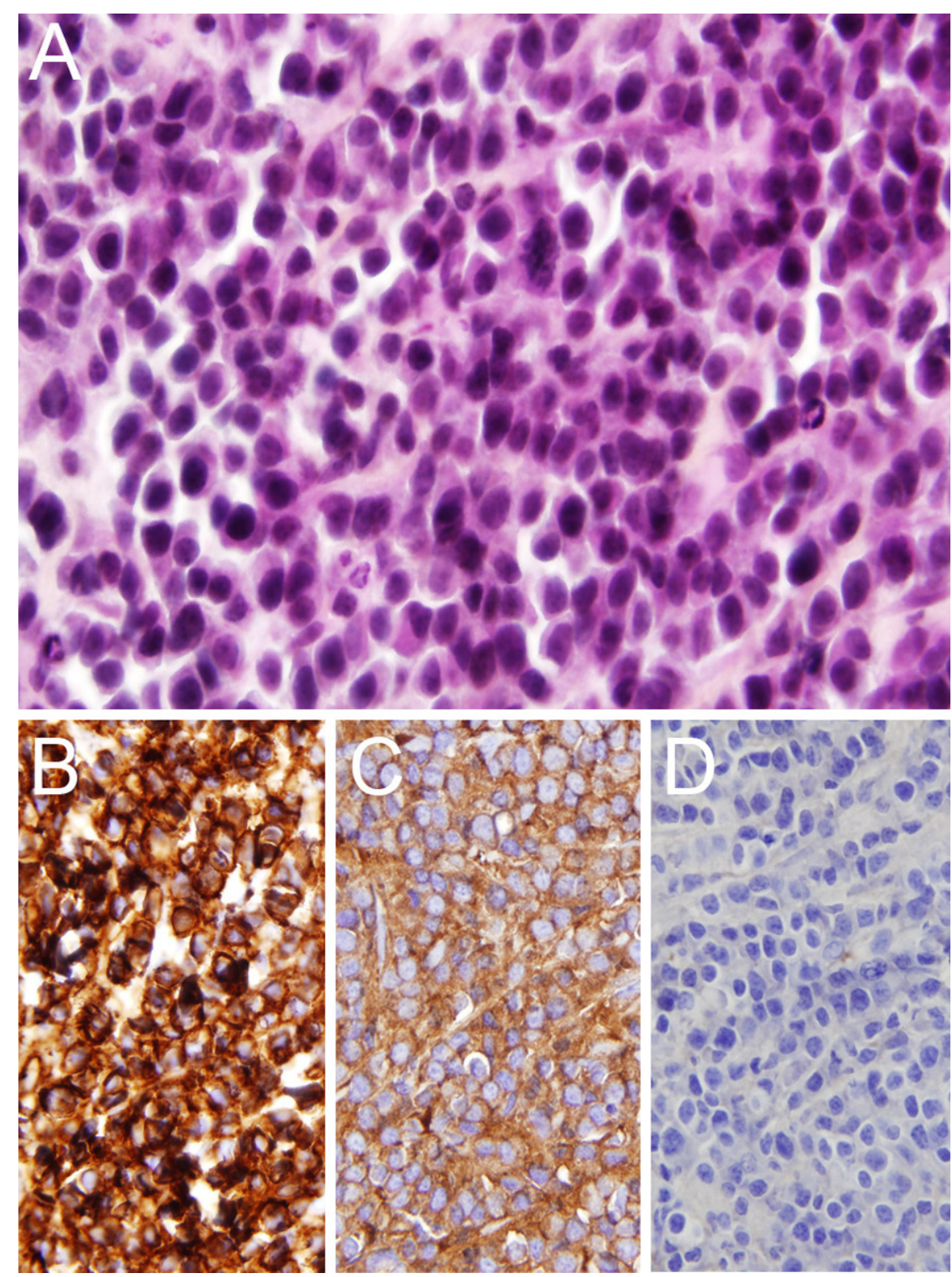

Figure 3. Histopathological examination of a retroperitoneal adenopathy. A) Sheets of plasma cells (hematoxylin-phloxin-saffron, original magnification $\times 40$ ). B) Widespread staining for CD138 (original magnification $\times$ 40). C) Widespread staining for lambda light chain (original magnification $\times 40$ ). D, Negative staining for kappa light chain (original magnification $\times 40$ ).

toneal plasmacytomas in association with multiple myeloma have been described $[9,10]$. Primary plasmacytomas of the lymph nodes are very rare and account for no more than $2 \%$ of all extramedullary plasmacytomas $[11,12]$. Primary plasmacytomas of retroperitoneal lymph nodes are even more infrequent. Based upon the criterion of the International Myeloma Work Group, a Primary lymph node plasmacytomas (PLNP) can only be diagnosed once the diagnosis of multiple myeloma has been excluded $[4,11]$. In this particular case, the high levels of $\mathrm{M}$ protein and the lytic bone lesions were not compatible with the diagnosis of PLNP. It seems there was an extramedullary extension of a plasma cell proliferation: an extraosseous multiple myeloma.

\section{Conclusion}

In conclusion, extraosseous tumoral proliferation is a rare presentation of a multiple myeloma. The present case is that of an IgA multiple myeloma with retroperitoneal lymph node extension. Extraosseous MM have been associated with $\operatorname{IgG}$ 
and IgA multiple myeloma. However, a more thorough evaluation of the characteristics of patients with MM presenting an extraskeletal plasma cell proliferation is needed in order to clarify the ambiguous findings of past trials $[3,8]$.

\section{References}

1. Patlas M, Khalili K, Dill-Macky MJ, Wilson SR. Spectrum of imaging findings in abdominal extraosseous myeloma. AJR Am J Roentgenol. 2004;183(4):929-932.

2. Innes J, Newall J. Myelomatosis. Lancet. 1961;1(7171):239-245.

3. Damaj G, Mohty M, Vey N, Dincan E, Bouabdallah R, Faucher C, Stoppa AM, et al. Features of extramedullary and extraosseous multiple myeloma: a report of 19 patients from a single center. Eur J Haematol. 2004;73(6):402-406.

4. Criteria for the classification of monoclonal gammopathies, multiple myeloma and related disorders: a report of the International Myeloma Working Group. Br J Haematol. 2003;121(5):749-757.

5. Kapadia SB. Multiple myeloma: a clinicopathologic study of 62 consecutively autopsied cases. Medicine (Baltimore). 1980;59(5):380-392.
6. Oshima K, Kanda Y, Nannya Y, Kaneko M, Hamaki T, Suguro M, Yamamoto R, et al. Clinical and pathologic findings in 52 consecutively autopsied cases with multiple myeloma. Am J Hematol. 2001;67(1):1-5.

7. Moulopoulos LA, Granfield CA, Dimopoulos MA, Kim EE, Alexanian R, Libshitz HI. Extraosseous multiple myeloma: imaging features. AJR Am J Roentgenol. 1993;161(5):1083-1087.

8. Puschel W, Kunath K. [Autopsy-statistical analysis of multiple myeloma (author's transl)]. Zentralbl Allg Pathol. 1977;121(4-5):381-388.

9. Terasaki Y, Okumura H, Sakai S, Ishiura Y, Yokawa S, Watanabe H, Saito K, et al. [Aggressive phase multiple myeloma with post-renal acute renal failure due to multiple extramedullary plasmacytomas]. Rinsho Ketsueki. 2007;48(7):565-570.

10. Talreja D, Slater LM, Dara P, Branson H, Armentrout SA. Multiple myeloma complicated by myelomatous obstructive uropathy. Cancer. 1980;46(8):1893-1895.

11. Menke DM, Horny HP, Griesser H, Tiemann M, Katzmann JA, Kaiserling E, Parwaresch R, et al. Primary lymph node plasmacytomas (plasmacytic lymphomas). Am J Clin Pathol. 2001;115(1):119-126.

12. Lin BT, Weiss LM. Primary plasmacytoma of lymph nodes. Hum Pathol. 1997;28(9):1083-1090. 